International Journal of Biomedicine | June 2021 - Volume 11, Issue Suppl_1: Abstracts from the Third Russian International Conference "Cryo-electron microscopy 2021: achievements and prospects"

ORAL ABSTRACT PRESENTATIONS

SESSION TITLE: STRUCTURE OF VIRUSES AND CHAPERONINS

DOI: 10.21103/IJBM.11.Suppl_1.OR6

\title{
Abstract OR-6: Baseplate Structure of Bacteriophage Phi812 and Mechanism of Cell Wall Binding and Penetration
}

Ján Bíňovský, ${ }^{1}$, Marta Šiborová ${ }^{1}$, Jiří Nováček ${ }^{1}$, Mark Van Raaij ${ }^{2}$, Pavel Plevka ${ }^{1}$

${ }^{I}$ Central European Institute of Technology, Masaryk University, Brno, Czech Republic

${ }^{2}$ Departmento de Estructura de Macromoleculas, Centro Nacional de Biotecnologia (CSIC), Madrid, Spain

Background: Antibiotic-resistant strains of Staphylococcus aureus cause human infections that are difficult to treat and can lead to death. Bacteriophage (phage) phi812K1/420 from the family Myoviridae infects $95 \%$ of clinical isolates of $S$. aureus and therefore is a promising candidate for a phage therapy agent. As the native phage particle approaches its host cell, phage receptorbinding proteins make a contact with the host cell wall. This interaction triggers a cascade of structural changes in the baseplate resulting in phage tail contraction and genome ejection. Mechanistic description of the baseplate reorganization, however, remains unknown.

Methods: Using cryo-electron microscopy (cryo-EM), we studied the baseplate of the phage phi812K1/420. Also, selected proteins involved in the host cell wall binding and penetration were produced in recombinant form and their structures were solved using X-ray crystallography and cryo-EM single-particle reconstruction.

Results: We reconstructed the phage baseplate in native and contracted states. The reconstruction of the native baseplate reaches a resolution of $4 \AA$, which enables us to discern individual protein structures. Solved protein structures will be fitted into the reconstruction of the contracted baseplate.

Conclusion: Our results provide the first structural characterization of contractile phage infecting a Gram-positive bacterium. Comparison of the two distinct baseplate states will allow us to describe the molecular mechanism of the initial stage of phage infection in detail.

Key Words: Staphylococcus aureus $\bullet$ bacteriophage $\bullet$ cryo-EM 
*Corresponding author: Ján Bíňovský. E-mail: jan.binovsky@ceitec.muni.cz

International Journal of Biomedicine. 2021;11 Suppl 1: S9.

doi: 10.21103/IJBM.11.Suppl_1.0R6

(C)2021 International Medical Research and Development Corporation 